\title{
Learning in practice
}

\section{Can gynaecology teaching associates provide high quality effective training for medical students in the United Kingdom? Comparative study}

Sally Pickard, Paula Baraitser, Janice Rymer, Johanna Piper

\begin{abstract}
Objectives To train laywomen to become professional patients in order to teach medical students speculum and bimanual examination, to assess their effectiveness in this role, and to incorporate this method of teaching into the undergraduate curriculum of a medical school in the United Kingdom.

Design Comparative study.

Setting Guy's, King's, and St Thomas's School of Medicine, London.

Participants 44 medical students trained by gynaecology teaching associates; 48 control students. Main outcome measure Skills in pelvic examination. Results Six laywomen were recruited and all successfully graduated to become gynaecology teaching associates. At assessment 1, in the third week of the reproductive and sexual health block, the mean score achieved by students trained by gynaecology teaching associates was 155, compared with 104 for control group students (difference in mean scores 51 (95\% confidence interval 41 to 61 ), $\mathrm{P}<0.001$ ). Similar results were obtained at assessment 2 , at the end of the attachment-the mean score for trained students was 148 , compared with a mean score of 114 for control group students (difference in mean scores 34 (21 to 46$), \mathrm{P}<0.001)$.

Conclusions Laywomen can be trained to teach pelvic examination to medical students in the United Kingdom. Students who receive this training have better skills than students who receive the traditional training alone.
\end{abstract}

\section{Introduction}

Gynaecology teaching associates are women trained to teach pelvic examination while themselves being examined. They usually work in pairs, with one acting as the patient and the other as the instructor. Gynaecology teaching associates are used in the United States, Canada, Australia, and Scandinavia. ${ }^{1-3}$ They are not used in the United Kingdom, for reasons that remain unclear. ${ }^{4}$ This teaching method is highly effective..$^{5-15}$ It is also an efficient use of resources and acceptable to medical students as well as to heads of department. ${ }^{16-19}$ In 1989 two medical schools in the United Kingdom were considering the use of gynaecology teaching associates, but little enthusiasm and some aversion to this approach was reported. ${ }^{4}$ Current teaching of intimate examinations in medical schools in the United Kingdom relies on students practising on anaesthetised patients or patients in clinics and on plastic models. ${ }^{49}{ }^{20}$ Problems inherent in these traditional methods include a lack of time in outpatient clinics, where the environment is often not conducive to learning, lack of opportunity to practise communication skills, and lack of feedback from patients. Training in intimate examinations needs to be improved, as some students are graduating unable to do an effective pelvic examination. ${ }^{20}$

We aimed to recruit and train laywomen to become professional patients in order to teach medical students speculum and bimanual examination, to assess their effectiveness in this role, and to incorporate this teaching method into the undergraduate curriculum of a medical school in the United Kingdom.

\section{Methods}

Recruitment, training, and assessment of gynaecology teaching associates

We placed posters in community reproductive health clinics and general practices. We interviewed prospective candidates and assessed them for their commitment to the project. We did a screening pelvic examination to ensure normal anatomy. Community Health South London NHS Trust employed successful candidates and paid them $£ 20$ /hour.

The curriculum delivered to the laywomen covered female anatomy and physiology, communication and teaching skills, infection control, and how to do a speculum and bimanual examination. The laywomen were able to practise the examination on each other, until they felt confident. Three of the authors (SP, PB, and JR) and an independent nurse assessor assessed their skills at the end of training.

\section{Training of students}

All 114 fourth year medical students starting their reproductive and sexual health block in January 2002 were eligible to take part. All students received the traditional teaching programme over a 12 week period. This consists of an introductory seminar including demonstration of pelvic examination on a manikin and an opportunity for students to practise this under
Department of Reproductive Health Care, Lewisham Primary Care Trust, London, SE5 7RN

Sally Pickard

staff grade

Department of

Reproductive

Health Care,

Southwark Primary

Care Trust, London, SE5 7RN

Paula Baraitser senior clinical medical officer

Department of Obstetrics and Gynaecology, Guy's, King's, and

St Thomas's School of Medicine, London SE1 9RT

Janice Rymer senior lecturer

Research Support Unit for Primary and Community Care, Southwark Primary Care Trust, Primary Care Trust 258 Waterloo Road, London SE1 8RG

Johanna Piper research officer

Correspondence to: S Pickard,

Department of Family Planning, Bedford House,

Havelock Place,

Shelton,

Stoke-on-Trent

ST1 4PR

sally.pickard@ nsch-tr.wmids.nhs.uk

BMJ 2003;327:1389-92

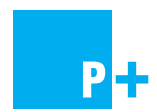

A figure appears on bmi.com 
Table 1 Total results from assessments 1 and 2

\begin{tabular}{|c|c|c|c|c|}
\hline Training received & $\begin{array}{c}\text { Mean score } \\
\text { (maximum 192) }\end{array}$ & Standard deviation & $\begin{array}{c}\text { Difference (95\% Cl) } \\
\text { in mean scores }\end{array}$ & $P$ value \\
\hline \multicolumn{5}{|l|}{ Assessment 1} \\
\hline GTA trained students $(n=43)$ & 155.51 & 17.97 & \multirow{2}{*}{51.0 (41 to 61$)$} & \multirow{2}{*}{$<0.001$} \\
\hline Non-GTA trained students $(\mathrm{n}=30)$ & 104.66 & 24.93 & & \\
\hline \multicolumn{5}{|l|}{ Assessment 2} \\
\hline GTA trained students $(n=31)$ & 148.06 & 22.94 & \multirow{2}{*}{34.0 (21 to 46$)$} & \multirow{2}{*}{$<0.001$} \\
\hline Non-GTA trained students ( $n=39$ ) & 114.51 & 28.81 & & \\
\hline
\end{tabular}

GTA=gynaecology teaching associate.

Table 2 Total results of students attending both assessments

\begin{tabular}{|c|c|c|c|c|}
\hline Training received & $\begin{array}{c}\text { Mean score } \\
\text { (maximum 192) }\end{array}$ & Standard deviation & $\begin{array}{l}\text { Difference }(95 \% \mathrm{Cl}) \\
\text { in mean scores }\end{array}$ & $P$ value \\
\hline \multicolumn{5}{|c|}{ GTA trained students $(\mathrm{n}=30)$} \\
\hline Assessment 1 & 152.30 & 17.80 & \multirow{2}{*}{$4.1(-6$ to 14$)$} & \multirow{2}{*}{0.42} \\
\hline Assessment 2 & 148.23 & 23.31 & & \\
\hline \multicolumn{5}{|c|}{ Non-GTA trained students $(\mathrm{n}=21)$} \\
\hline Assessment 1 & 111.05 & 26.36 & \multirow{2}{*}{$-11.0(-22$ to 1$)$} & \multirow{2}{*}{0.06} \\
\hline Assessment 2 & 121.90 & 24.72 & & \\
\hline
\end{tabular}

GTA=gynaecology teaching associate.

supervision. Students subsequently build on these skills by examining patients in clinics and theatre.

Initial statistical calculations indicated that to detect an effect size of 0.6 at $80 \%$ power and $5 \%$ significance, we needed 45 students in each group. We expected a minimum difference in scores of $3.5 \%$ between trained and non-trained students. ${ }^{8}$ We randomly allocated 48 students to receive the training. A few students allocated to be trained could not attend their session and arranged for a colleague to attend instead. The teaching session lasted approximately two hours and involved two gynaecology teaching associates teaching four students. After demonstrating speculum and bimanual examination, the associates guided each student through a gynaecological consultation, giving them the opportunity to practise communication skills and technical skills and providing individual feedback. In addition to practising these skills themselves, all students had the opportunity to observe and learn from their peers.

\section{Assessment of students}

We first assessed all students doing a speculum and bimanual examination in the third week of their reproductive and sexual health block (assessment 1). At this point all students had participated in the initial demonstration of examination technique on the first day of their reproductive and sexual health block, and all those allocated to training by gynaecology teaching associates had completed this training. We assessed them again at the end of their 12 week attachment (assessment 2). All 44 students trained by gynaecology teaching associates were allocated to be assessed, and we randomly selected controls from the remaining 70 students. If a control student could not attend the allocated session, and informed the researchers in advance, another student was selected from the pool of remaining controls. The figure on bmj.com shows the progress of students through the project.

Two independent assessors rated 34 items of the students' performance on a two or three point scale (0-1 or $0-2$; maximum score 120$)$. The patient assessed six items on a three point scale (0-2; maximum score 12). The independent assessors and the patient assessed overall performance for communication skills and technical skills on 10 point Lickert-type scales (maximum score 30 for each). Each student could score a maximum of 192 for each assessment.

The independent assessors were experienced senior doctors and nurses (trained in speculum examination) in the department of obstetrics and gynaecology or the community department of family planning and reproductive health care. The assessors were unaware of which students had received training by gynaecology teaching associates.

\section{Statistical analysis}

We analysed the data with SPSS for Windows (version 10.00). We added students' scores for each section of the assessment and collated them to form an overall score. Statistical analysis showed that the data were normally distributed, which allowed independent $t$ tests to be used. The $t$ tests compared the difference in the mean scores between the two groups of students for each section of the assessment and for their overall scores at assessment 1 . We repeated this analysis for scores at assessment 2. We used a paired sample $t$ test to compare the scores over time for students attending both assessments. We used the "Statistics with confidence" package to calculate confidence intervals for the difference between mean scores of students who received training by gynaecology teaching associates and students who did not. ${ }^{21}$

\section{Results}

We received more than 40 responses to the job advertisement, interviewed nine women, and recruited six women on to the training programme. All six successfully completed the training and were recruited to train medical students.

Table 1 summarises the number of students attending the assessments and their overall scores at both assessments. Students trained by gynaecology teaching associates scored significantly higher $(\mathrm{P}<0.001)$ than students who had not received this training. To assess whether the students' skills altered over time, we compared the scores for the students who attended both 
Table 3 Overall assessments for communication skills and technical skills

\begin{tabular}{|c|c|c|c|c|}
\hline Training received & $\begin{array}{c}\text { Mean score } \\
\text { (maximum 30) }\end{array}$ & Standard deviation & $\begin{array}{l}\text { Difference ( } 95 \% \mathrm{Cl}) \\
\text { in mean scores }\end{array}$ & $P$ value \\
\hline \multicolumn{5}{|c|}{ Communication skills (maximum score $\mathbf{3 0}$ ) } \\
\hline \multicolumn{5}{|l|}{ Assessment 1: } \\
\hline GTA trained students $(n=43)$ & 25.67 & 2.68 & \multirow{2}{*}{8.0 (6 to 9$)$} & \multirow{2}{*}{$<0.001$} \\
\hline Non-GTA trained students $(\mathrm{n}=30)$ & 18.13 & 3.92 & & \\
\hline \multicolumn{5}{|l|}{ Assessment 2: } \\
\hline GTA trained students $(n=31)$ & 24.16 & 3.64 & \multirow{2}{*}{$5.0(3$ to 7$)$} & \multirow{2}{*}{$<0.001$} \\
\hline Non-GTA trained students $(\mathrm{n}=39)$ & 19.13 & 5.32 & & \\
\hline \multicolumn{5}{|l|}{ Technical skills (maximum score 30 ) } \\
\hline \multicolumn{5}{|l|}{ Assessment 1: } \\
\hline GTA trained students $(n=43)$ & 25.25 & 2.98 & \multirow{2}{*}{$10.0(8$ to 11$)$} & \multirow{2}{*}{$<0.001$} \\
\hline Non-GTA trained students $(\mathrm{n}=30)$ & 15.67 & 4.23 & & \\
\hline \multicolumn{5}{|l|}{ Assessment 2: } \\
\hline GTA trained students $(n=31)$ & 22.71 & 3.91 & \multirow{2}{*}{6.0 (4 to 8$)$} & \multirow{2}{*}{$<0.001$} \\
\hline Non-GTA trained students $(\mathrm{n}=39)$ & 16.77 & 5.03 & & \\
\hline
\end{tabular}

GTA=gynaecology teaching associate.

assessments, as shown in table 2. The scores achieved by the 30 students trained by gynaecology teaching associates did not alter significantly over time $(\mathrm{P}=0.42)$. The scores achieved by the 21 control group students attending both assessments showed an increase over time of borderline significance $(\mathrm{P}=0.06)$. We also compared the differences in scores between the two assessments for the two groups of students. Scores altered significantly over time $(\mathrm{P}=0.019)$ among the control students (mean difference 10.86) compared with the trained students (mean difference $-4.07)$. Although the trained students scored significantly higher than the control students at both assessments, when we compared the mean change in scores the control students showed a greater improvement in performance over time than did the trained students.

Both independent assessors and the gynaecology teaching associate patient gave each student an overall score on a scale of 1-10 for their communication skills and technical skills. The trained students scored significantly higher than the students in the control group with respect to both communication skills and technical skills ( $\mathrm{P}<0.001$ for both) (table 3$)$.

As there was some swapping between the two groups, a sampling bias could have been introduced, with better students taking advantage of the opportunity to learn from gynaecology teaching associates in place of their less interested colleagues. To examine this further we compared the abilities of the two groups by analysing their results in the end of year objective structured clinical examination. The end of year examination scores of trained students $(n=43$, mean score 67.28) and non-trained students $(\mathrm{n}=48$, mean score 64.85) were not significantly different $(\mathrm{P}=0.112)$. Although more motivated students are more likely to have attended both assessments, a further analysis comparing the end of year results for students attending both assessments with students attending only one assessment showed no significant difference in scores $(\mathrm{P}=0.666)$.

\section{Discussion}

This study is the first to show that a gynaecology teaching associate programme can be incorporated into the undergraduate curriculum of a large medical school in the United Kingdom. The results obtained

\section{What is already know on this topic}

Gynaecology teaching associates are used to train medical students in pelvic examination in the United States and in many European countries

This method of teaching is both effective and acceptable

Gynaecology teaching associates are not currently used in the United Kingdom

\section{What this study adds}

Women can be recruited and trained to become gynaecology teaching associates in the United Kingdom

Gynaecology teaching associates are effective in teaching pelvic examination to medical students in the United Kingdom

are consistent with the literature and confirm that this method of teaching is highly effective. ${ }^{5-15}$ We found that students who received additional training by gynaecology teaching associates were more skilled at pelvic examination than students trained in the conventional manner. These skills were maintained over the 12 week reproductive and sexual health block, and both technical and communication skills were improved. Although the mean scores for students trained by traditional methods alone increased after completion of the reproductive and sexual health block, this was of borderline significance $(\mathrm{P}=0.06)$. This suggests that current teaching of intimate examinations is inadequate, as a clear improvement in students' skills over their clinical attachment would be expected.

The six women recruited to become gynaecology teaching associates may have been exceptional in their ability to acquire complex examination and teaching skills and in their commitment and enthusiasm for the project. Our results may not be applicable to less able or less committed teaching associates.

\section{Conclusion}

It is possible to recruit and train women to become gynaecology teaching associates in the United King- 
dom. The addition of a gynaecology teaching associate programme to traditional teaching methods for pelvic examination improves students' technical and communication skills. Such a programme would be a useful addition to the curriculum of medical schools in the United Kingdom.

Contributors: SP, PB, and JR jointly designed the study; recruited, trained, and supported the gynaecology teaching associates; and wrote the paper. SP and JP organised the medical student training and assessment programme. JP collected and analysed the data and commented on all drafts of the paper. Funding: SP and PB are recipients of a grant from the Guy's and St Thomas's Charitable Foundation.

Competing interests: None declared.

Ethical approval: The local ethics committee advised that approval should be obtained from the dean of the medical school. This was duly granted.

1 Beckmann CRB, Spellacy WN, Yorke A, Barzansky B, Cunningham RP. Initial instruction in the pelvic examination in United States and Canada 1983. Am J Obstet Gynecol 1985;151:58-60.

2 Abraham S. Vaginal and speculum examination in the medical curricula. Aust NZJ Obstet Gynaecol 1995;35:56-9.

3 Wijma B. [Gynaecologic examination; a role-playing for two.] Larkartidningen 1998;95:1125-9 (in Swedish).

4 Biggs JS, Harden RM, Howie P. Undergraduate obstetrics and gynaecolBiggs J S, Harden RM, Howie P. Undergraduate obstetrics and gynaecol-
ogy in the United Kingdom and Republic of Ireland 1989. Br J Obstet Gynaecol 1991:98:127-34.

5 Kretzschmar RUM. Evolution of the gynaecology teaching associate: an education specialist. Am J Obstet Gynecol 1978;131:367-73.

6 Livingstone RA, Ostrow DN. Professional patient-instructors in the teaching of the pelvic examination. Am J Obstet Gynecol 1978;132:64-7.
7 Holzman GB, Singleton D, Holmes TF, Maatsch JL. Initial pelvic examination instruction: the effectiveness of three contemporary approaches. Am J Obstet Gynecol 1977;129:124-9.

8 Kleinman DE, Hage ML, Hoole AJ, Kowlowitz V. Pelvic examination instruction and experience: a comparison of laywoman-trained and physician-trained students. Acad Med 1996;71:1239-43.

9 Guenther SM, Laube DW, Matthes S. Effectiveness of the gynaecology teaching associate in teaching pelvic examination Skills. J Med Educ 1983;58:67-9.

10 Shain RA, Crouch SH, Weinberg PC. Evaluation of the gynaecology teaching associate versus pelvic model approach to teaching pelvic examination. J Med Educ 1982;57:646-8.

11 Beckmann CRB, Barzansky BM, Sharf BF Meyers K. Training gynaecological teaching associates. Med Educ 1988;22:124-31.

12 Johnson GH, Brown TC, Stenchever MA, Gabert HA, Poulson AM, Warenski JC. Teaching pelvic examination to second year medical students using programmed patients. Am J Obstet Gynecol 1975;121:714-7.

13 Rochelson BL, Baker DA, Mann WJ, Monheit AG, Stone ML. Use of male and female professional patient teams in teaching physical examination of the genitalia. J Reprod Med 1985;30:864-6.

14 Tolmas HC. Adolescent pelvic examination: an effective practical approach. Am J Dis Child 1991;145:1269-71.

15 Lessermann J, Luke CS. An evaluation of an innovative approach to teaching the pelvic examination to medical students. Women and Health 1982;7:31-42.

16 Beckmann CRB, Lipscomb GH, Williford L, Bryant E, Ling FW Gynaecological teaching associates in the 1990s. Med Educ 1992;26:105-9.

17 Plauche WC, Baugniet-Nebrija W. Students' and physicians' evaluation of gynecologic teaching associate program. J Med Educ 1985;60:870-5.

18 Vontver L, Irby D, Rakestraw P, Haddock M, Prince E, Strenchever M. The effects of two methods of pelvic examinations instruction on student performance and anxiety. J Med Educ 1980;55:778-85.

19 Cohen DL, Wakeford R, Kessel RWI, McCullough LB. Teaching vaginal examinations (letter). Lancet 1988;2:1375

20 Cardoza L. Teaching vaginal examination (letter). BMJ 1992;305:113.

21 Altman DG, Machin D, Bryant TN, Gardner MJ. Statistics with confidence Second ed. Bristol: BMJ Books, 2000.

(Accepted 11 September 2003)

\section{Paws for thought}

Ellie, our family's 2 year old Labrador bitch, jumped into the boot of the car, avulsed a claw, and let out an uncharacteristic wail. An anxious and rather sleepless night was had by all. I put her on a course of dog biscuits (two every four hours) to try to cheer her up. The next morning, after some discussion, I telephoned our local veterinary practice and was soon sitting in the waiting room with time to reflect on the experience.

I had telephoned at 840 am and was waiting to be seen at $855 \mathrm{am}$. The receptionist was also the veterinary nurse and was therefore able to triage the problem. She correctly anticipated that an operation might be necessary and, far better, that this should take place as early as possible in the day. The practice is paperless, and she had immediate access to Ellie's details.

The waiting room itself was fresh and bright with "easy clean" floors for obvious reasons. Posters of breeds of guinea pig adorned the walls. Among the other owners waiting there was a great sense of camaraderie and sharing of information about their pets' medical histories.

The consultation was brief and vet centred. A 30 second history was followed by a quick examination and an explanation of the severity of the problem and the rationale for treatment. I was given clear and concise information, and, on the basis of this, my verbal consent was obtained. I nodded in agreement to the ordained plan.

I was strangely relieved that it had been an appropriate use of veterinarian time. I hid this emotion from Ellie, sensing that she may find my feelings somewhat inappropriate. She was sedated and taken away for examination. After 20 minutes one of the other partners informed me that Ellie would need a general anaesthetic. Again it was a vet centred discussion, with opportunity to ask questions but ultimately for me to consent to the plan.

I picked up Ellie at $115 \mathrm{pm}$ and admired her neat white bandage with blue paw prints. A third partner in the practice gave me advice on care of the bandage and details of the antibiotic and analgesic cover she had received.

I was left pondering the outcomes. Firstly, a healthy dog; secondly, a cost itemised bill; thirdly, clear telephone advice when the white bandage with blue paw prints came off; and, fourthly, a validation of my decision to attend. Above all, however, I had the opportunity to reflect on the day's events.

I was impressed by the speed of access to treatment, with the role of the vet nurse acting as receptionist and therefore triaging. I was surprised that I felt the need for it to be a valid use of the vet's time. The vet centred consultation reduced my feeling of responsibility for the decisions taken and emphasised a need to trust the expert. I wondered if the process of direct billing encouraged the giving of clear information and obtaining consent before each procedure. I was struck by the paradox of experiencing benefits from a vet centred consultation whereas, as a doctor, I have consciously tried to move towards a patient centred model.

The issue of trust highlighted the broader view of the consultation not in isolation but in the context of an ongoing relationship. Personalised veterinary care and continuity of care are provided by the practice as a whole rather than an individual vet. Finally, I was surprised by the camaraderie and sharing of information among pet owners. The average general practice waiting room feels somewhat uncomfortable in comparison.

I hadn't expected Ellie's misfortune to provide a learning opportunity, but it is surprising what can happen when you pause for thought.

Alan Johnstone higher professional training fellow in general practice, University of Edinburgh

We welcome articles up to 600 words on topics such as A memorable patient, A paper that changed my practice, My most unfortunate mistake, or any other piece conveying instruction, pathos, or humour. Please submit the article on http:// submit.bmj.com Permission is needed from the patient or a relative if an identifiable patient is referred to. We also welcome contributions for "Endpieces," consisting of quotations of up to 80 words (but most are considerably shorter) from any source, ancient or modern, which have appealed to the reader. 